\title{
Globetrotting firms: Canada's health biotechnology collaborations with developing countries
}

\author{
Monali Ray, Abdallah S Daar, Peter A Singer \& Halla Thorsteinsdóttir \\ A survey of Canadian biotech firms reveals that their biotech collaborations with developing countries are not only \\ significant but also increasingly reciprocal in terms of the exchange of financial resources and technological know-how.
}

\begin{abstract}
To stay competitive in health biotech, firms have had to form strategic alliances that often cross international borders-and increasingly can involve companies in developing countries. Capacity in the health biotech field is no longer limited to a handful of high-income Western countries. Developing countries themselves have been building up their expertise ${ }^{1}$ and starting their own firms in the field ${ }^{2-4}$.

Although the potential benefits of collaboration with partners in developing countries ('North-South collaboration') in health biotech are considerable, relatively little is known about whether these benefits are being realized and whether 'Northern' firms are globalizing by forming linkages with 'Southern' partners. The aim of this study is to help fill this gap by presenting results from a survey of firms working in the health biotech sector in Canada about their collaborations with partners in developing countries. Even though the focus is on Canada's experience in North-South collaboration, the opportunities we identify through our research can also be harnessed by biotech companies in other Northern countries. In the following analysis, we examine the extent of the collaboration of Canadian health biotech firms with partners in developing countries, map where the main linkages lie and explore the main characteristics and outputs of these collaborations.
\end{abstract}

Monali Ray, Abdallah S. Daar, Peter A. Singer and Halla Thorsteinsdóttir are at the McLaughlin-Rotman Centre for Global Health, University Health Network and University of Toronto, Toronto, Ontario, Canada; and Halla Thorsteinsdóttir is also at the Dalla Lana School of Public Health, University of Toronto, Toronto, Ontario, Canada.

e-mail: halla.thorsteinsdottir@utoronto.ca

\section{North-South collaborations: Canada as a model}

There are several reasons why North-South collaboration is valuable for developed countries' health biotech firms. Emerging economies, such as China, India and Brazil, have large populations, with increasing spending power and high demand for health biotech products $^{2-5}$. Collaborating with local partners is a first step in being able to access these vast markets. Furthermore, North-South collaboration can help mitigate the high risks and costs faced in health biotech product development. For example, the costs of manufacturing, clinical trials and R\&D can be lower in developing countries, and thus North-South collaboration may reduce the cost of the overall drug development process. Finally, North-South collaboration can help firms access complementary assets. The multiplicity of scientific and technical expertise needed to enable health biotech product development can be found worldwide, including within firms and institutions in developing countries ${ }^{1,6}$.

On the other side, firms in developing countries enter North-South collaborations for reasons similar to those of their Northern partners. They too want to collaborate to access new markets in the North with populations that have a high spending power ${ }^{4,7,8}$. Firms in developing countries also seek collaboration with companies from the North to reduce risk in product development and to access financing ${ }^{7}$. Moreover, they seek these types of collaborations to gain access to scientific and technical expertise in developed countries ${ }^{3,7,9}$. Regulatory expertise can be of particular importance to firms in developing countries that are taking their first steps in innovation ${ }^{10}$.

We chose to focus our study on collaborations between Canada and developing coun- tries. Canada is ranked sixth in the world in terms of number of publications in international peer review journals ${ }^{11}$, and it also ranks second only to the United States ${ }^{12}$ in terms of the number of health biotech companies. Even so, its commercialization record is weak. Only ten firms account for $70 \%$ of the market capitalization of all Canadian biotech firms, and revenues predominantly come from the domestic market ${ }^{13}$. Furthermore, even though the United Kingdom had a similar number of biotech firms and patents to Canada in 2003, it had three times more revenue than Canada ${ }^{13}$. Traditionally, Canadian firms have focused on forming alliances with firms just south of its border, seeking market opportunities in the United States ${ }^{14,15}$. To succeed in health biotech, a more global approach is required, and this can include partnerships with emerging economies and developing countries ${ }^{16}$.

To gauge the frequency and characteristics of Canada's collaboration with developing

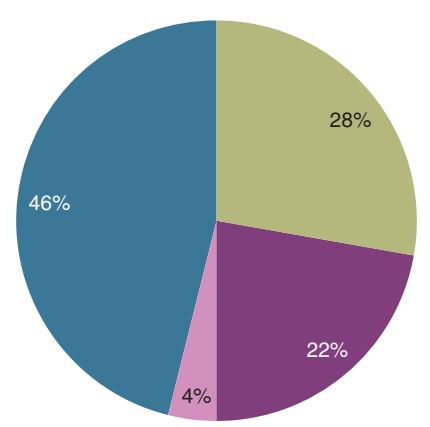

North-North only

Neither North-South nor North-North

Both North-South and North-North

North-South only

Figure 1 Extent of international collaboration by Canadian health biotech firms. 


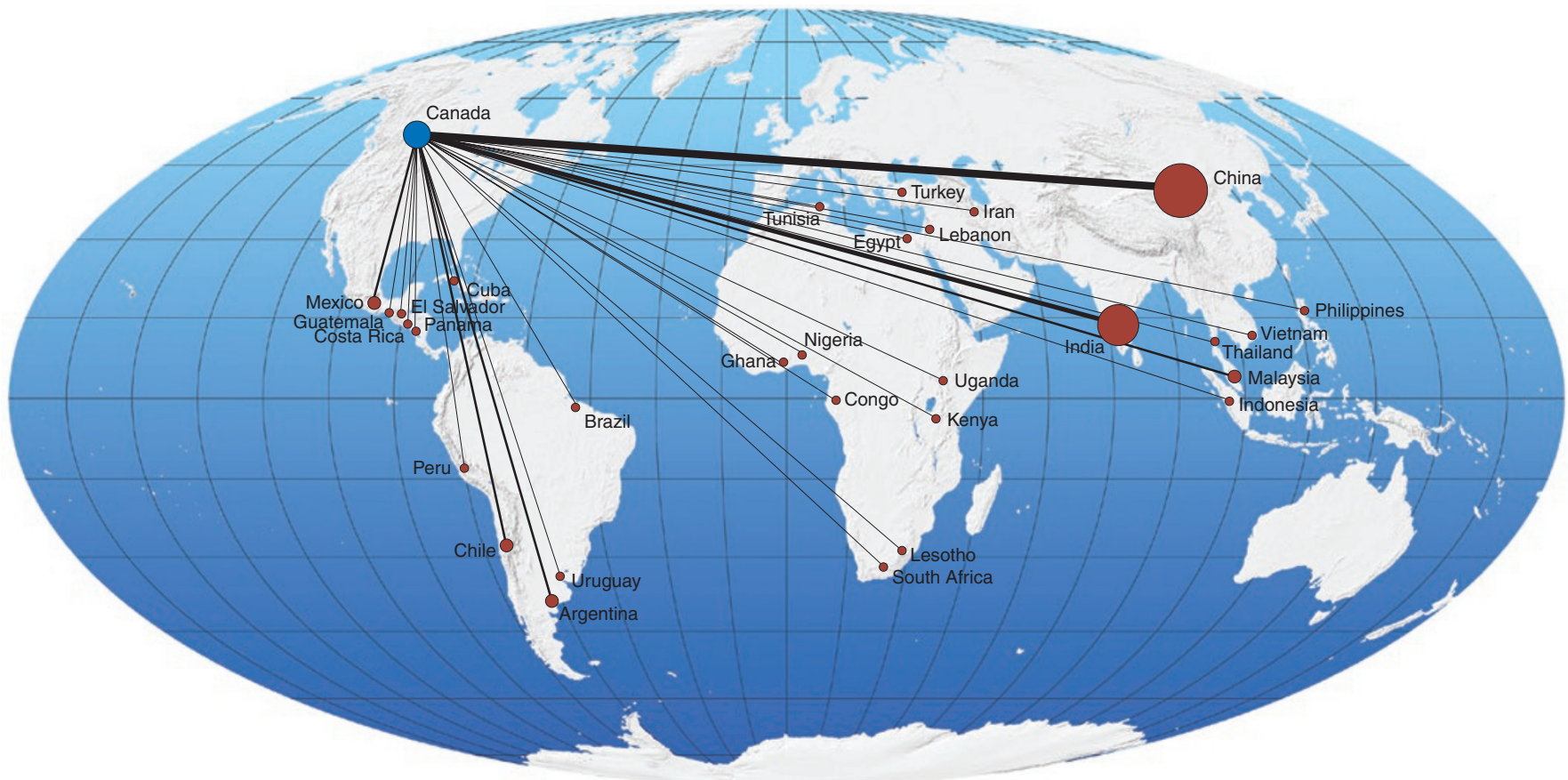

Figure 2 The geography of Canada's North-South collaborations. Both the size of the red node and the width of the connecting line represent the number of collaborations the developing country has with Canadian firms.

countries, we sent a brief survey to all the health biotech firms we could identify in Canada-a total of 259 firms (see Supplementary Methods for a detailed description of the study methodology). We asked firms whether they collaborated with developing countries and if so, to list the collaborations and provide further information regarding these collaboration initiatives, such as information on the reasons for the collaboration and the activities involved. We gave the firms a broad definition of 'collaboration', which included any work jointly undertaken by firms and organizations contributing to the production of knowledge, products and services in health biotech. A total of 181 firms completed the survey (a response rate of 70\%), the results of which are presented below.

\section{How much collaboration is occurring?}

Our survey results show that a quarter (26\%) of Canadian health biotech firms are involved in North-South collaboration (Fig. 1). Most firms that collaborate with developing countries are also actively collaborating with developed countries, which indicates that they seek alliances widely around the globe. In total, Canadian firms reported 82 North-South collaboration initiatives with developing countries. Many of these firms have more than one such collaboration initiative. In comparison, nearly half $(46 \%)$ of Canadian firms reported collaborations with partners in other developed countries only. About a quarter of Canadian firms (28\%) report having no international collaborations. A previous study from our group ${ }^{17}$ normalized the data on the number of firm collaborations with developing countries with information on the sizes of the biotech sector in select developed countries. We found that Canada's level of North-South collaboration did not reach the level of collaboration by biotech firms in the United States but was on par with the collaboration levels of firms from the European Union. The levels of North-South collaboration we observe for Canada's firms are therefore likely to be similar to the ones observed for most Northern countries, except the United States.

To learn more about the collaborators, we collected information regarding the trade listing (public or private) of the firms we surveyed. Among the 181 respondent firms, 54 are publicly listed and 127 are private. A substantial number of both public and private firms (77\% and 63\%, respectively) are involved in North-North collaborations. When it comes to North-South collaborations, Canadian public and private firms seem to be engaged in these to similar degrees ( $24 \%$ and $27 \%$, respectively). Thus, our data does not indicate a difference in the levels of international collaboration between public and private firms.

\section{What developing countries are involved?}

To examine where Canadian health biotech firms' collaborations with developing countries lie, we visualized the linkages (Fig. 2) using the software Ucinet 6 (Analytic Technologies,
Lexington, Kentucky, US; http://www. analytictech.com/ucinet/).

Canadian firms have collaborations in all main regions of the world. Their strongest developing-country linkages are with China (22 of the 82 North-South collaboration initiatives reported in the survey) and with India (17 collaboration initiatives). Both China and India have intensified their efforts to build domestic health biotech capacity in recent years ${ }^{18,19}$. This, combined with the large market potential available in these countries, is likely to make them lucrative partners for Canadian firms. The top four developed countries that Canadian firms collaborate with are the United States (116 collaboration initiatives), UK (35 collaboration initiatives), Germany (23 collaboration initiatives) and Japan (18 collaboration initiatives). Thus, our results indicate that Canadian firms' collaborations with India and China are approaching or surpassing their collaborations with the leading developed countries outside of the US in the health biotech field.

The survey found Canadian firms also work with countries in Latin America (21 collaboration initiatives in total). Several countries in Latin America, such as Brazil and Cuba, are active in health biotech ${ }^{7,20}$. The continent's relative proximity to Canada and its wealth of natural resources may be additional factors that make firms based in Latin America attractive partners for Canadian firms.

In contrast, the level of Canadian firms' partnerships with countries in East Asia and the 
Pacific ( 8 collaboration initiatives in total), the Middle East and North Africa (5 collaboration initiatives in total) and sub-Saharan Africa (9 collaboration initiatives in total) at this time is relatively low.

Almost all (90\%) of Canadian firms' NorthSouth collaborations involved at least one type of formal arrangement among participants. joint R\&D agreements. Licensing agreements were cited quite frequently, with over a fifth of the North-South collaboration initiatives being based around them. Joint ventures were rarer, being reported in only $12 \%$ of the collaboration initiatives. The establishment of a subsidiary was reported in $13 \%$ of the collaboration initiatives. Subsidiaries are being set up not only by Canadian firms in developing firms in Canada.

\section{Characteristics of collaborations}

Canadian health biotech firms' collaborations often involve different types of activities; $40 \%$ of firms report involving two or more types of activities in a single North-South collaboration initiative. The collaborative activities cover all stages of the health biotech value chain (Fig. 3).

Collaboration initiatives involving joint distribution ranked highest in frequency (30\% of the 82 North-South collaboration initiatives). However, collaborations involving joint R\&D followed closely (28\% of the collaboration initiatives). R\&D collaborations are important for firms because these not only help firms generate new, proprietary products, but also enhance a firm's ability to identify, assimilate and exploit new knowledge that can provide the basis for further $R \& D^{21}$. These types of gains and the intensity of knowledge flows in $\mathrm{R} \& \mathrm{D}$ collaborations are not typically present These ranged from distribution agreements to countries, but also by developing countries'

in collaborations that are limited to distribution activities.

Clinical trials, manufacturing, laboratory services and contract research are also reported to be frequent collaboration activities. The collaborations also involve provision and use of supplies (including raw materials, active pharmaceutical ingredients and so forth) and provision of training activities, but these occur at lower frequencies (Fig. 3).

Leveraging competitive advantages. Our survey results indicate that Canadian health biotech firms have relatively strong distribution collaborations with China and India, the two most populous countries in the world (Fig. 4a). Africa is the world's second-most-populous continent after Asia (http://www.worldatlas. com/aatlas/infopage/content.htm), and so it is interesting to note that collaborations involving distribution and marketing with partners in African countries are on par with such collaborations in Latin American countries, even though Latin America is closer geographically to Canada. Although there is not a direct relationship between population size and market demand, as many people in the more populous countries cannot afford health biotech products, the emphasis that Canadian firms place on distribution and marketing ties with African countries may reflect the latter continent's expanding market potentials.

Canadian firms report having strong $R \& D$ linkages with Chinese and Indian partners (Fig. $4 \mathrm{~b}$ ). Because these two countries have been building their capacity for innovative research, this is not surprising ${ }^{18,19}$. Canadian firms also report significant joint $\mathrm{R} \& \mathrm{D}$ activities with partners in Latin American countries, such as Chile, and it is noteworthy that the firms have closer R\&D ties to Latin America than marketing and distribution ties. We can look

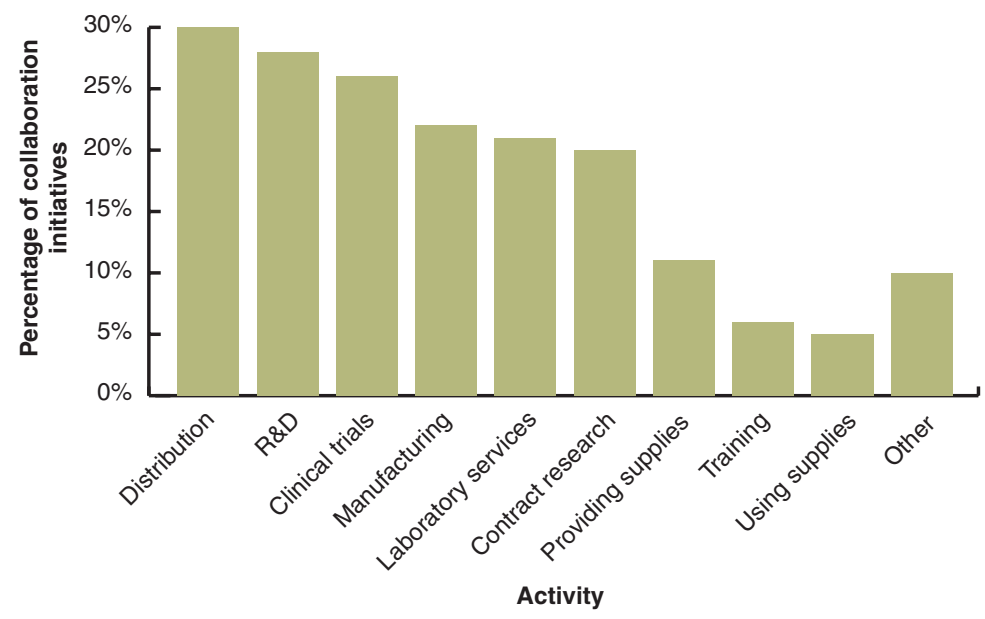

Figure 3 Joint activities in Canada's North-South collaborations. at joint distribution and $\mathrm{R} \& \mathrm{D}$ linkages as being at opposite ends of the spectrum of health biotech collaborations. As we move away from a focus on distribution to R\&D and a stronger emphasis on new-to-the world knowledge generation, we seem to lose connections to Africa and the Middle East but gain connections to Latin America, especially to Chile and Mexico.

Manufacturing-related activities are frequently cited in Canadian firms' collaborations with Chinese organizations. Nearly half (47\%) of their manufacturing collaboration is with partners in China. This is perhaps not surprising as China is the second largest producer of pharmaceutical ingredients and generic drugs in terms of value, after the US, and its firms are moving into the biotech field ${ }^{22}$. Chinese firms can leverage cost-effective manufacturing ${ }^{3}$ in partnerships with foreign partners.

Canadian firms' contract research activities are particularly strong with Indian organizations versus with other countries. A total of $43 \%$ of Canadian firms' collaboration in contract research is with India. This fits well with previous studies that show Indian contract research organizations to be leveraging strengths in the areas of synthetic chemistry and bioinformatics to offer foreign partners cost-effective investigations in India ${ }^{2,19}$.

We note that 'using supplies' has a higher relative representation in Canadian firms' collaborations with partners in Latin American countries than in their collaborations with partners in other developing countries: $75 \%$ of Canadian firms' collaboration initiatives involving this activity are with partners in Latin American countries. The relatively high emphasis on 'using supplies' in collaboration with Latin America may reflect initiatives to harness the continent's terrestrial biodiversity.

The study results suggest that Canadian firms may be leveraging the special strengths of their developing countries' partners (technological, niche areas or other resources) in the collaborations. This reflects the active role developing countries have in the collaborations and suggests that developing countries are not simply on the receiving end of these alliances.

We were interested in exploring whether Canadian firms have technological strengths that are particularly attractive to developing countries' firms and fuel the collaboration. We classified the technological foci of the Canadian firms that reported being involved in R\&D collaborations with developing countries according to information from their websites. The firms have a wide range of technological foci, and discovery tools, 
biologics and diagnostics firms are all significantly involved in R\&D collaboration with developing countries (see Supplementary Methods online). Our interviews with experts in health biotech in developing countries, which are a part of an ongoing case study on Canada's collaboration with developing countries, support the notion that developing countries wish to work with Canadian firms because they perceive Canada as being strong in health biotech in general, rather than being attracted to Canada's strengths in any particular subsection of health biotech.

Rationale for collaborations. The survey results suggest that Canadian firms' collaborations with developing countries are driven by a complex mix of reasons, and, in many cases, respondents reported several reasons for initiating a single collaboration initiative.
We note that gaining access to developing countries' markets was the reason most frequently cited by Canadian firms for collaborating with developing countries $(66 \%$ of the North-South collaboration initiatives). This is consistent with the observation that the collaborations commonly involve marketing and distribution activities.

The second most frequently cited reason by Canadian health biotech firms was to provide
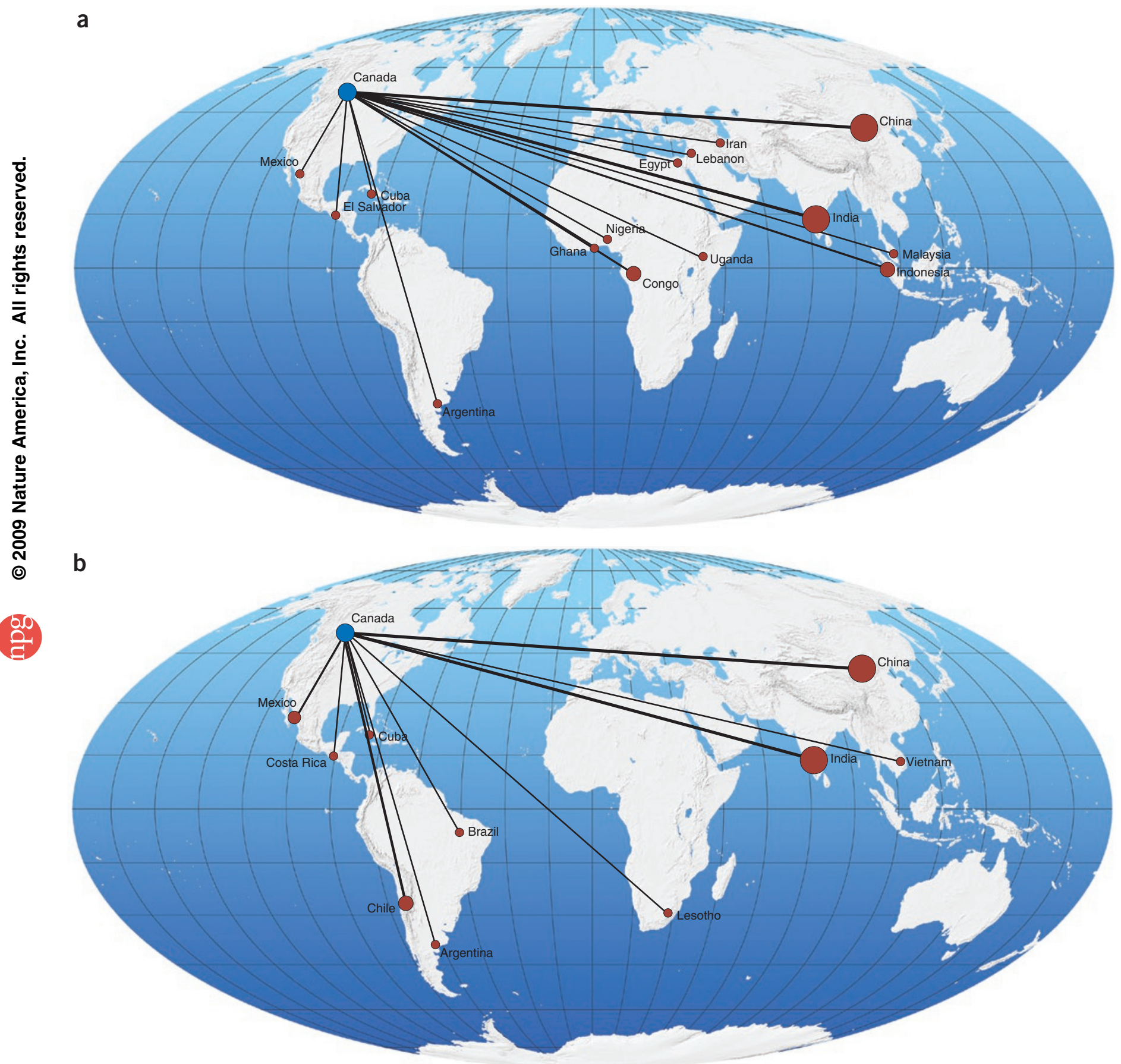

Figure 4 The geography of select collaborative activities. (a) Distribution and marketing activities. (b) Research \& development activities. 


\section{Box 1 Role reversal? South-to-North resource flows}

A key to successful biotech collaboration is reciprocity and equal contribution among partners. Traditionally, financial resources and science-intensive knowledge have come from the richer North, so it is a sign of changing times that in some cases these resources are now originating from the South, flowing into Canadian firms and contributing to their successes.

The Biosyntech-Piramal Healthcare partnership is an example of collaboration in which financial resources from a developing country have enabled a Canadian health biotech firm to continue with its innovative R\&D activities. The Canadian firm Biosyntech (Montreal; http://www.biosyntech.com/en/) is involved in the development of thermogels for tissue repair and drug delivery. After encountering difficulty in raising financing from North American venture capitalists, company management approached one of India's largest pharmaceutical firms, Piramal Healthcare (Mumbai; http://www.npilpharma. com/about-us/piramal-group.html), for funding. Piramal Healthcare, in exchange for distribution and research collaboration agreements, made a CDN\$6 million (US \$5.4 million) equity investment in the Canadian firm in 2006. As a result of this investment by the Indian firm, Biosyntech was able to stay afloat and raise subsequent funding from North American investors. The Canadian firm credits its Indian partner for keeping it alive, and Biosyntech's has now been able to push its proprietary therapy for localized cartilage lesion repair into clinical testing.

An example of another type of resource flow from South to North is the joint venture between the Canadian firm YM BioSciences (Mississauga, Ontario, Canada; http://www. ymbiosciences.com/) and the Cuban research institution Centre for Molecular Immunology (Havana). In this case, it is Southern technology and know-how that is being transferred to the Northern partner, rather than funding. The Canadian firm does not conduct its own basic research. Its first in-licensed technology was a cancer therapy technology from the Centre for Molecular Immunology in 1995. Cuban scientists did the original basic research and are manufacturing the anticancer, epidermal growth factor receptor-targeting humanized monoclonal antibody nimotuzumab. Today, YM BioSciences is conducting phase 1 to 3 trials of nimotuzumab in Europe, North America, Asia and Latin America, itself and through several companies that have licensed development rights from YM BioSciences. The trials are being conducted for various cancer types, including nonsmall-cell lung, glioma, esophageal, colorectal, pancreatic, prostate, cervical and breast. Nimotuzumab is approved in several countries for the treatment of head and neck cancers and glioma. Licensing technology from its Southern partner has enabled YM BioSciences to develop an advanced portfolio in oncology; the firm has been named among Canada's top ten life sciences companies two years in a row.

knowledge to their developing countries' partners ( $37 \%$ of the collaboration initiatives). The firms report accessing knowledge from their developing countries' partners to be the third most frequent reason for their collaborations ( $24 \%$ of the collaboration initiatives). These findings seem to indicate bidirectional knowledge flows between Canadian firms and their partners in developing countries.

Canadian firms also cited both providing financing to developing country partners and accessing funding from partnerships with developing country firms $(6 \%$ and $7 \%$ of the collaboration initiatives respectively) as reasons for their North-South collaborations. This reflects, once again, that resources are not necessarily streaming from the North to the South in Canada's collaboration with developing countries. Indeed, there are recent examples of firms in developing countries providing financing to firms in Canada (see Box 1).
In the survey, Canadian firms were given space to include any additional comments. In 13 of the collaborations, the comments indicated that Canadian firms are choosing to work with firms in developing countries to minimize their development costs and gain access to cheaper labor and production. The Canadian firms also cited altruistic reasons (for example, "helping developing countries" and "to bring wealth we have here over there") for their collaborations, reflecting a moral aspect to partnerships with firms in developing nations. Still, based on our survey, we cannot conclude that developing countries typically receive direct financial benefits from their health biotech collaborations with Canada. In fact, the opposite seems to be true as there is significant evidence that Canada's North-South health biotech collaborations involve bidirectional knowledge and other flow of resources that leverage strengths offered by both participating countries.
Collaborations are firm-initiated. We asked Canadian health biotech firms to indicate who initiated their collaborations with developing countries. The results indicate that the partnerships were almost always initiated by the partnering firms themselves. Over half of the collaborations $(52 \%$ of the North-South collaboration initiatives) were initiated by the Canadian firms only, and over a quarter (29\% of the collaborations) were jointly initiated by Canadian and developing-country partners. About $12 \%$ of the North-South collaboration initiatives were initiated by partners from developing countries only. The survey responses did not indicate expatriates or diaspora communities as playing a role in helping to set up the partnerships: only 1 out of 82 collaborations credited expatriates as helping to initiate the collaboration. No collaborations at all were initiated by international organizations.

What is notable is that the collaborations seem to have arisen without much assistance from governmental agencies in Canada or in developing countries-only 7 out of 82 collaboration initiatives received government help in establishing their collaboration. Previous case-study research has suggested that a major challenge faced by Canadian biotech firms in penetrating emerging markets is a lack of support in establishing initial linkages with potential partners ${ }^{23}$. With more government assistance, we might therefore expect to observe an even higher level of Canadian firm collaboration with companies in developing countries. In this regard, the establishment of bridging organizations, such as International Science and Technology Partnerships Canada (ISTPCanada; Ottawa, Ontario, Canada), which works at the junction of domestic and international government desks to promote the country's science and technology collaboration with the emerging economies of China, India and Brazil (http://www.istpcanada.ca/home/ index.html), is a positive step, although more needs to be done.

Collaborations fuel the product pipeline. We asked Canadian firms to specify the types of output from each of their collaborations. The data indicate that these partnerships are productive (Fig. 5) as almost all the collaborations (90\%) report some form of shared output. More than a quarter (29\%) of the collaborations have joint products in the pipeline, and $15 \%$ of the collaborations already have joint products in the market. This reflects a strong product focus. Joint patenting is, however, rare, with only $4 \%$ of the collaborations reporting joint patents as an output of collaborations. 


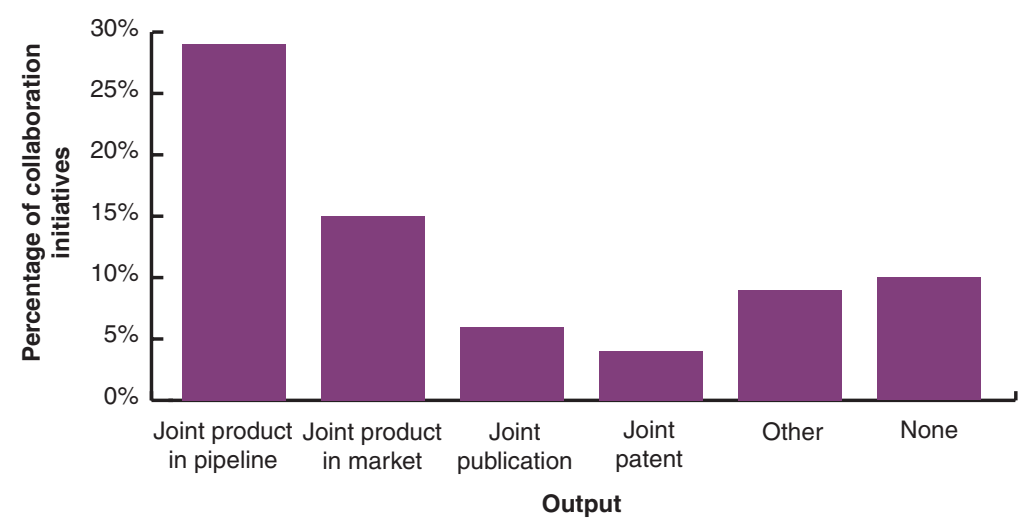

Figure 5 Joint output in Canada's North-South collaborations.

A few firms indicated that the collaboration with developing countries has led to 'other' forms of joint outcomes ( $9 \%$ ). They specified these to include joint $\mathrm{R} \& \mathrm{D}$ projects, entering into distribution agreements and beginning clinical phase studies, among other things. Thus, North-South collaboration can be important to firms achieving milestones of the drug development process, as well as distribution and marketing agreements. We provide examples of these in Boxes 1-4.
Ongoing case study research indicates that most Canadian health biotech firms are taking their first steps in North-South partnerships. Their limited joint patenting further strengthens the notion that these types of collaborations are young, and it is likely that we will see more joint patenting as the partners become more familiar with one another and collaborations progress. There are great expectations that the collaborations will open up new markets and strengthen the firms' innova- tion potentials. Health biotech is increasingly global in scope, and without global partnerships the firms will not be able to remain competitive. We do not, however, have survey data on further benefits of the collaboration. As the collaborations seem to be young, they are unlikely to have already led to significant increases in revenues.

To see whether there are any differences between firms that are involved in NorthSouth collaborations versus those that are not, we selected the public firms in our data set and compared financial information of those publicly listed Canadian firms that reported having North-South collaboration to those that did not. Both the average total assets and R\&D expenditures were similar between the firms that have been involved in North-South collaboration and those that have not (Table 1). We do note, however, that average total revenues of firms that have North-South collaborations are nearly four times higher than firms that do not have such partnerships. Even after removing the top revenue earner from the group that has North-South collaborations, the adjusted average total revenue is double that of the other group. Thus, our data suggests that Canadian public health biotech

\section{Box 2 Collaborating with the Dragon of the East}

China and Canada affirmed their commitment to work together by signing a bilateral science and technology agreement in January 2007. Collaborating across the Pacific Ocean is a natural development for the two Asia-Pacific Economic Cooperation (APEC) states and is undoubtedly facilitated by the fact that Canada has had a continuous immigration stream from China and, as a result, a sizeable Mandarin- and Cantonese-speaking population. In health biotech research, their collaboration is fueled by their populations' shared health problems. Both have aging populations and thus a high burden of non-communicable disease (http://www.who.int/ whosis/whostat/EN_WHS08_Full.pdf). In addition, communicable diseases spread easily between the two countries. This was illustrated by the severe acute respiratory syndrome (SARS) epidemic in 2003, which spread to Canada a matter of weeks after its outbreak in China; indeed, Canada had the third-highest number of reported cases in the world ${ }^{24}$. It is, therefore, not altogether surprising that our survey on Canadian firms' health biotech firms showed China as Canada's foremost developing-country partner in the field. The Canadian firms are likely to be attracted to the large market in China, which is home to over a billion people, as well as to China's R\&D and manufacturing strengths. Canada is likely to be an attractive partner to China because it has a strong track record in biotech and has developed promising technologies in the field.

In 2008, ProMetic Life Sciences (Montreal), a Canadian biopharmaceutical company, entered into collaboration with the Wuhan Institute of Biological Products (WIBP; Wuhan, China), a subsidiary of China National Biotec Group (CNBG), for ProMetic's affinity-separation technology for extracting and purifying proteins from human plasma at high yields. According to Lifang Wang, president and CEO of CNBG, "The integration of ProMetic's technologies into WIBP's existing manufacturing infrastructure will significantly increase WIBP's manufacturing capacity and enable WIBP to better meet the ever-growing demand in China." Initial products targeted include thrombin, fibrinogen, intravenous immunoglobin, anti-hepatitis B immunoglobin, anti-rabies immunoglobin and anti-tetanus immunoglobin. The strategic alliance is therefore aimed at strengthening WIBP's manufacturing capacity through innovative technology and broadening ProMetic's reach into a rapidly expanding market (http://www.prometic.com/ en/prometic/index.php).

Another Canadian firm actively working with Chinese partners to penetrate the Chinese drug market is Welichem Biotech (Vancouver, British Columbia, Canada; http://www.welichem. com/index.php). Welichem's discovery platform enables the identification of novel anti-inflammatory or antiproliferative compounds from bacteria symbiotic with insects and nematodes. The company's lead drug WBI-1001, a non-steroidal antiinflammatory cytokine modulating compound is being developed as a cream for the treatment of psoriasis, eczema and inflammatory bowel disease. In 2005, Welichem entered into a strategic partnership with Weihe Pharmaceutical (Yuxi, China) and Celestial Pharmaceuticals (Shenzhen, China) for the cost-effective, development and marketing of novel drugs discovered through the Canadian company's platform. The Chinese partners planned a US\$ 50 million investment over three years into Welichem and the firms are establishing a R\&D laboratory in China. Joint R\&D at the preclinical level and transfer of senior management has thus far been conducted to deepen the synergies between the partners. 


\section{Box 3 The global face of clinical trials}

Taking a healthcare product from concept to proof-of-concept and finally regulatory approval is a long, arduous process. Firms, therefore, commonly choose to carry out testing of product safety and efficacy in partnerships. Our survey of health biotech firms in Canada shows that these partnerships can cross the world and be between Canada and developing countries' firms. It is important for firms to work with experienced local partners to assess effectiveness and safety of a trial product in different populations thereby gaining information for optimal design of the product and to navigate the local regulatory system.

In 2006, the Juravinski Cancer Centre's (Hamilton, Ontario, Canada) clinical trial group was chosen as a trial site by Piramal Healthcare (Mumbai, India) to pursue its first-in-human trials of its novel anticancer molecule. Piramal Healthcare is interested in entering its proprietary products in global markets, including in North America, and as such decided to conduct trials at North American sites. It also is taking its first steps in innovative discovery and wanted to test its novel product in a country with a regulatory system that has a strong track record in testing innovative drug candidates. The trial was conducted at the Juravinski Cancer Centre under International Committee for Harmonization/Good Clinical Practice and Health Canada regulatory guidelines. Hal Hirte, Chief of Oncology at the Centre, notes that due to the "reciprocities" between the Canadian regulatory system and that of the US FDA, it is easier for clinical data collected in Canada to be accepted in the US in comparison to data collected elsewhere in the world. It is also cheaper for Piramal Healthcare to carry out initial trials in Canada than in the United States because Canada's universal healthcare system covers part of healthcare costs. The Juravinski Cancer Centre is now in discussion with Piramal Healthcare to continue with phase 2 trials of the anticancer drug.

Elsewhere, SpectraDigital (Guelph, Ontario, Canada; http://www.spectradigital.net/ index.php), a small Canadian firm interested in tapping into the Brazilian market with its diagnostic technology, has partnered with FK Biotec (Porto Alegre, Brazil; http:// www.fkbiotec.com.br), a Brazilian immunodiagnostics firm. SpectraDigital's diagnostic technology platform uses light-scattering measurements and image processing techniques to allow inexpensive diagnosis of HIV, Plasmodium, multi-drug-resistant tuberculosis bacilli and various types of tumors - all diseases of local relevance in Brazil. As a small firm, SpectraDigital's business model depends on partnerships to implement its platform in global markets. It is relying on the infrastructure, contacts, distribution channels, financial investment and regulatory know-how of FK Biotec to demonstrate proof of concept and take the final product to market. Satish Deshpande of SpectraDigital notes that his firm is able to enter the Brazilian market owing to its linkages with an experienced local partner while larger firms have stayed out of this market because of difficulties faced in understanding and negotiating the regulatory channels there. From FK Biotec's perspective, however, CEO Fernando Kreutz says, "It's not only a simple clinical trial. It is more than that because we are actually involved in further development of the product, finding new applications, improving the range of product applicability."

firms that have North-South collaborations generate higher revenues than those that do not. Still, as our data are limited, we cannot attribute the companies' increased revenues to their North-South collaboration, as an alternative explanation may be that the firms that have the highest revenues are the most outward looking.

Table 1 Canadian health biotech public firms: 2007 financial data

\begin{tabular}{lcc} 
Financial benchmark & $\begin{array}{c}\text { Firms with North-South } \\
\text { collaborations (US\$ millions) }\end{array}$ & $\begin{array}{c}\text { Firms without North-South } \\
\text { collaborations (US\$ millions) }\end{array}$ \\
\hline Average total assets & 33.6 & 40.4 \\
Average R\&D expenditure & 11.9 & 15.5 \\
Average total revenues & 16.3 & 4.4
\end{tabular}

successes of initiatives promoting Canadian firms' collaboration with developing countries in health biotech.

Although we have focused our research on Canadian firms' collaborations, the findings from the study are relevant to other developed countries because it gives an indication of the potential of North-South collaboration in general to strengthen innovation in health biotech. The findings may be useful to firms interested in global expansion, to research groups considering entrepreneurial alliances and to government policymakers who are in a position to influence innovation, development or foreign affairs policies in both developed and developing countries.

There are several conclusions from our study of entrepreneurial collaborations between Canadian health biotech firms and developing countries. First, these types of partnerships are widespread. Canada has frequent ties to developing countries, with over a quarter of its health biotech firms collaborating with developing countries. Firms that engage in NorthSouth collaboration seem to be involved in a number of collaboration initiatives with their partners. The survey results show Canadian firms report having a similar number of collaboration with companies in the developing economies of China and India as they do with companies in developed countries, such as Germany, Japan and France. Developing countries that have invested in their domestic health biotech sectors seem best poised to participate in global health biotech networks, and their respective strengths attract collaboration with Northern partners.

Second, collaborations have a relatively strong focus on R\&D activities. Responses from Canadian health biotech firms show that $\mathrm{R} \& \mathrm{D}$ activities are nearly as common as distribution and other end-stage commercialization activities in their North-South collaboration initiatives, reflecting a significant degree of knowledge-intensive collaboration between Canadian firms and their developing country partners. This focus on joint R\&D has the potential to increase learning and innovation in both the South and the North.

Third, our study results suggest that Canadian firms' collaborations with developing countries are based on leveraging both partners' competitive strengths. Developing countries may be relying on existing strengths in specific areas-technological, service-based or resource-based-to work with Canadian firms. Bidirectional transfer of knowledge is an important reason for forming these NorthSouth partnerships. We also note bidirectional flow of capital between Canadian and developing countries' partners. The collaborations are 
not unidirectional in terms of contributions: developing countries' firms and organizations are active participants in their joint initiatives with Canadian firms.

Fourth, the majority of Canada's entrepreneurial health biotech partnerships have been initiated by the participating firms without external intervention either from Canada or the partnering country. International organizations and diaspora communities have not played a significant role in encouraging North-South collaboration. Canadian firms have received some help from government agencies, such as the ministries of trade or foreign affairs, in both the North and the South, but this has been limited in nature. There is clearly a great deal more bridging that could be done to ensure that North-South collaboration is able to thrive and meet its potential.

Finally, the collaborations are strongly focused on products. Our data show that North-South partnerships are productive and almost all of them have led to some shared output. The most common output is a joint product in the pipeline, although some collaborations have a joint product already on the market. Considering the focus on product development, collaborations could, in the future, be a strong force in innovation. There is, however, reason to believe that the partnerships are nascent, and, considering the high uncertainty of drug development, it is premature to evaluate their benefits in terms of marketed new-to-the world innovation, revenues and job creations.

Overall, our survey indicates that Canadian firms have a strong interest in building partnerships in the health biotech sector with firms in developing countries. On the basis of this research, several recommendations can be made to strengthen this process with inputs from various stakeholders. Canadian firms that are looking into new market opportunities should increasingly consider firms in developing countries. By partnering with these firms, they can gain access to the latter's local marketing intelligence and distribution networks. Our research demonstrates that the partnerships do not have to focus solely on marketing activities but can also strengthen innovation pipelines. Developing countries' firms are collaborating with Canadian biotech firms to gain access to their technological expertise and experience in product development. Canada has strengths in biotech, reflected in its high publication rate in international peer-reviewed journals and large number of firms active in the field ${ }^{12,13}$. For developing countries' firms taking their first steps in new-to-the world innovation, it is likely to be beneficial to form partnerships with firms that already have experience with the various phases of clinical trials on innovative products and a system geared to regulate such innovative efforts. Furthermore, as Canada is geographically close to the United States and has some cultural similarities, with strong parallels in regulatory oversight, collaboration with Canadian firms provides developing countries' firms with a stepping stone to the lucrative US market.

Governments in developed countries should realize that the global innovation landscape is changing and can increasingly involve contributions from developing countries. So far, innovation policies of developed countries have primarily focused on internal 'national' visions, or have prioritized international partnerships with other developed countries to drive innovative behavior. They have paid limited attention to the potential of collaborating with developing countries to stimulate domestic innovative capabilities. What our results suggest is that this needs to change. To maintain global competitiveness in health biotech, developed countries must broaden the scope of their innovation agendas to include partnerships with developing countries. Innovation policies and foreign affairs policies need to be integrated to promote collaboration and innovation in a global-

\section{Box 4 International commercialization of needle-free insulin}

In 2001, Frost \& Sullivan awarded its Product Differentiation Innovation Award to the Canadian firm Generex Biotech (Toronto; http://www.generex.com/) for a proprietary formula (containing cyclodextrin, a mucobioadhesive polymer carboxmethycellulose, the surfactant sodium lauryl sulfate, viscosity-control polymer hydroxypropyl methycellulose and urea peroxide) that facilitates the delivery of large-molecule drugs to the buccal mucosa. Generex has developed Oral-Lyn, a formulation of insulin mixed with the delivery formulation that patients can self administer via a device (RapidMist) capable of aerosolizing the drug by means of a chemical propellant. Oral-Lyn thus offers needle-free delivery of the hormone to patients with type I and type II diabetes. Early on, Generex realized that in addition to conducting testing and clinical trials in North America, turning to international commercial partners-particularly in developing countries, where the diabetes epidemic is expected to swell, according to the World Health Organization (Geneva) ${ }^{25}$-would be a critical component of its strategy to increase support, endorsement and ultimately acceptance of its product worldwide and at home.

Generex took its first step toward international registration and commercialization of Oral-Lyn in Ecuador. After gaining clearance from the Ecuadorian Ministry of Public Health, the company in 1998 began clinical testing of the product's safety and efficacy in collaboration with local investigators at the Instituto de Endocrinologia Metabolismo y Reproducción (IEMYR; Quito, Ecuador). Generex also entered into an alliance with PharmaBrand, a local Ecuadorian pharmaceutical firm, and together the partners successfully gained regulatory approval to commercialize Oral-Lyn in Ecuador in 2005. The alliance gave a boost to PharmaBrand and strengthened its position in Latin America. Generex also benefitted from its connections in Ecuador. Presentation of Oral-Lyn's clinical trial data by IEMYR researchers at many international conferences significantly increased awareness of the product by a global audience. Oral-Lyn's successful registration in Ecuador renewed investor confidence in Generex. It also served as a springboard to Generex forming further Oral-Lyn licensing and distribution agreements with partners across the globe, including SciGen (Hefei, China), Adcock Ingram (Johannesburg, South Africa), Dongsung Pharmaceutical (Seoul, South Korea), Shreya (Mumbai, India) and Banaja (Jeddah, Saudi Arabia). 
Biotech investors must also embrace the fact that innovation in health biotech increasingly involves global players and components. To recoup developmental costs, firms need to market their products widely around the world. For many small firms, investors are the main advisors for business strategies, and an increasing appreciation of the benefits of North-South innovation and its role in business models is likely to be important for the future success of biotech enterprises. To maintain global competitiveness in health biotech, developed countries must broaden the scope of their innovation agendas to include partnerships with developing countries. To do so, different stakeholders must align their strategies so they can work together toward the common goal of promoting cost-effective health innovation of mutual benefit to the North and the South.

\section{ACKNOWLEDGMENTS}

The authors thank all the firms that responded to the survey and generously shared their expertise and time. We also thank J. Clark for comments on the manuscript and J. Chadder and M. Li for help with data collection. This project was funded by the Canadian Institutes of Health Research and supported by the McLaughlinRotman Centre for Global Health. The McLaughlinRotman Centre for Global Health, Program on Ethics and Commercialization is primarily supported by Genome Canada through the Ontario Genomics Institute, the Ontario Research Fund, and the Bill and Melinda Gates Foundation. Other matching partners are listed at http://www.mrcglobal.org/. M.R. is supported by a Canadian Institutes of Health Research Training Award. A.S.D. and P.A.S. are supported by the
McLaughlin Centre for Molecular Medicine. P.A.S. is supported by a Canadian Institutes of Health Research Distinguished Investigator award. H.T. is supported by a New Investigator Award from the Canadian Institutes of Health Research.

\section{COMPETING INTERESTS STATEMENT}

The authors declare competing financial interests: details accompany the full-text HTML version of the paper at http://www.nature.com/ naturebiotechnology/.

1. Thorsteinsdóttir, H., Quach, U., Daar, A.S. \& Singer, P.A. Conclusions: promoting biotechnology innovation in developing countries. Nat. Biotechnol. 22 (suppl.), DC48-DC52 (2004)

2. Frew, S.E. et al. India's health biotech sector at a crossroads. Nat. Biotechnol. 25, 403-417 (2007).

3. Frew, S.E. et al. Chinese health biotech and the threebillion patient market. Nat. Biotechnol. 26, 37-53 (2008).

4. Rezaie, R. et al. Brazilian health biotech-fostering crosstalk between public and private sectors. Nat. Biotechnol. 26, 627-644 (2008).

5. Rao, S. The rise of the BRICS: what does it mean for Canada? (Conference Board of Canada, 2008).

6. Wagner, C.S. The new invisible college: science for development (Brookings Institution, Washington, DC, 2008).

7. Thorsteinsdóttir, H., Saenz, T.W., Quach, U., Daar, A.S. \& Singer, P.A. Cuba - innovation through synergy. Nat. Biotechnol. 22 (suppl.), DC19-DC24 (2004).

8. Chataway, J., Tait, J. \& Wield, D. Frameworks for pharmaceutical innovation in developing countries - the case of Indian pharma. Technol. Anal. Strateg. 19, 697-708 (2007).

9. Mytelka, L.K. Pathways and policies to (bio)pharmaceutical innovation systems in developing countries. Ind. Innov. 13, 415-435 (2006).

10. Bower, J.D. \& Sulej, J.C. The Indian challenge: the evolution of a successful new global strategy in the pharmaceutical industry. Technol. Anal. Strateg. 19 611-624 (2007).

11. Thorsteinsdottir, H., Daar, A.S. \& Singer, P.A. Health biotechnology publishing takes-off in developing coun- tries. Int. J. Biotechnol. 8, 23-42 (2006).

12. van Beuzekom, B. \& Arundel, A. OECD biotechnology statistics. (OECD, Paris, 2006).

13. Munn-Venn, T. \& Mitchell, P. Biotechnology in Canada: a technology platform for growth (Conference Board of Canada, 2005)

14. Traore, N. Canadian biotech firms: extent of networking activities and commercialization success. Innov. Anal. Bull. 3, 13-14 (2001).

15. Biotecanada. Canadian and US biotechnology companies forging new partnerships at the 2007 Bio International Convention (May 2007). <http://www. lifesciencesbc.ca/News/>

16. Dufour, P. Taking the (right?) fork in the road: Canada's two-track approach to domestic and international science and technology. Sci. Public Policy 29, 419-430 (2002).

17. Melon, C.C. et al. A survey of South-North health biotech collaboration. Nat. Biotechnol. 27, 229-232 (2009).

18. Zhenzhen, L. et al. Health biotechnology in Chinareawakening of a giant. Nat. Biotechnol. 22 (suppl.), DC13-DC18 (2004).

19. Kumar, N.K. et al. Indian biotechnology_rapidly evolving and industry led. Nat. Biotechnol. 22 (suppl.), DC31-DC36 (2004).

20. Ferrer, M., Thorsteinsdóttir, H., Quach, U., Singer, P.A. \& Daar, A.S. The scientific muscle of Brazil's health biotechnology. Nat. Biotechnol. 22 (suppl.), DC8-DC12 (2004).

21. Coe, D.T., Helpman, E. \& Hoffmaister, A.W. North-south R\&D spillovers. Econ. J. 107, 134-149 (1997).

22. Yusuf, S., Nabeshima, K. \& Perkins, D.H. China and India reshape global industrial geography. in Dancing with Giants: China, India and the Global Economy. Pages 35-66. Editors: Winters, L.A. \& Yusef, S. The World Bank: Washington, D.C. (2007).

23. Taylor, A.D. et al. North-South partnerships-a study of Canadian firms. Nat. Biotechnol. 25, 978-979 (2007).

24. Zhong, N.S. \& Wong, G.W.K. Epidemiology of severe acute respiratory syndrome (SARS): adults and children. Paediatr. Respir. Rev. 5, 270-272 (2004).

25. Wild, S., Roglic, G., Green, A., Sicree, R. \& King, H. Estimates for the year 2000 and projections for 2030 . Diabetes Care 27, 1047-1053 (2004). 